\title{
Mechanisms in Tridax procumbens leaf extract reversal of paroxetine-induced erectile dysfunction in corpus cavernosum of male Wistar rats
}

\author{
Shakiru Ademola Salami ${ }^{1}{ }^{*}{ }^{\oplus}$, Hussein Mofomosara Salahdeen ${ }^{1}$, Zainab Ashabi Balogun ${ }^{1}$, \\ Babatunde Adekunle Murtala ${ }^{1}$, Yinusa Raji ${ }^{2}$
}

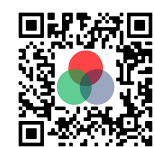

Use your smartphone to scan this QR code and download this article

\begin{abstract}
${ }^{1}$ Department of Physiology, Lagos State University College of Medicine, Ikeja Lagos State Nigeria

${ }^{2}$ Department of Physiology, College of Medicine, University of Ibadan, Ibadan Nigeria

Correspondence
\end{abstract}

Shakiru Ademola Salami, Department of Physiology, Lagos State University College of Medicine, Ikeja Lagos State Nigeria

Email: shakiru.salami@lasu.edu.ng

\section{History}

- Received: May 04, 202

- Accepted: Jun 11, 2021

- Published: Jun 30, 2021

DOI : 10.15419/bmrat.v8i6.678

\section{Check for updates}

\section{Copyright}

(c) Biomedpress. This is an openaccess article distributed under the terms of the Creative Commons Attribution 4.0 International license.

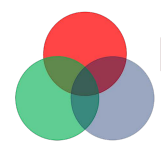

BioMedPress

The Open Access Publisher

\begin{abstract}
Introduction: Aqueous leave extract of Tridax procumbens (AETPL) is reported to improve erectile functions; however, the mechanism is unclear. This study investigates the mechanism involved in the contractile activity of the corpus cavernosum after AETPL treatment of paroxetine-induced erectile dysfunctional adult male Wistar rats. Methods: A total of 20 male Wistar rats were categorized into four groups of five and treated orally for four weeks: Group 1 (distilled water), Group 2 (paroxetine $10 \mathrm{mg} / \mathrm{kg}$ ), Group 3 (paroxetine + AETPL $100 \mathrm{mg} / \mathrm{kg}$ ), and Group 4 (paroxetine + Viagra $0.5 \mathrm{mg} / \mathrm{kg}$ ). Contractile responses of excised corpus cavernosum strips (CS) were determined in response to acetylcholine (ACh), phenylephrine (PHE), potassium chloride (KCl), and calcium chloride $\left(\mathrm{CaCl}_{2}\right)$, and after incubation in L-NAME, indomethacin, nifedipine, adenosine, caffeine, nicorandil, and acetovanillone. Results: The relaxation response (\%) of CS to ACh was significantly inhibited in the paroxetine group compared to the AETPL- and the Viagra-co-treated group. Pre-incubation in L-NAME considerably enhanced the percentage relaxation in groups co-treated with AETPL and Viagra. Groups co-treated with AETPL and Viagra significantly inhibited contraction in response to cumulative doses of $\mathrm{CaCl}_{2}$. Contractile responses of $\mathrm{CS}$ to cumulative doses of PHE after incubation in caffeine and adenosine were considerably inhibited in groups co-treated with AETPL and Viagra. Similarly, nicorandil $\left(10^{-4} \mathrm{M}\right)$ enhanced the percentage relaxation to cumulative doses of ACh $\left(10^{-9}-10^{-5} \mathrm{M}\right)$ in groups co-treated with AETPL and Viagra. The pre-incubation of CS with acetovanillone $\left(10^{-4} \mathrm{M}\right)$ enhanced the percentage relaxation to ACh across groups. Conclusion: Erectile dysfunction was reversed by AETPL-induced antioxidant/NADPH oxidase inhibitor activity, reduced calcium sensitivity, activation of ATP-sensitive $\mathrm{K}^{+}$channel, and endothelial Nitric Oxide (NO) release.

Key words: Acetovanillone, Adenosine, Caffeine, Erectile dysfunction, Erectile tissues, KATP channel, Nicorandil, Reversal, Tridax procumbens
\end{abstract}

\section{INTRODUCTION}

The Tridax procumbens leaf contains several bioactive phytochemicals that include a rich presence of flavonoids, alkaloids, hydroxycinnamates, tannins, phytosterols, as well as a modest amount of lignans carotenoids $^{1,2}$.

There have been extensive reports on the vasorelaxant activities of the Tridax procumbens aqueous leaf extract (AETPL). In normotensive animals, AETPL reduced arterial blood pressure and heart rate in a dose-dependent manner ${ }^{3}$. AETPL also caused both endothelium-dependent and endotheliumindependent vasorelaxant effects in the aortic ring of normotensive rats ${ }^{4}$. Furthermore, Salahdeen et al. ${ }^{5}$ reported that calcium-dependent mechanisms are involved in the vasorelaxant activities of AETPL; specifically, non-specific and non-competitive inhi- bition of calcium influx and mobilization from stores were reported $^{5}$.

Furthermore, a mechanistic study by Salahdeen et al. ${ }^{6}$ observed that the stimulation of prostacyclin production and opening of small conductance calciumactivated potassium channels are involved in the vasorelaxant activities of AETPL in normotensive rats. In hypertensive rats, treatment with AETPL significantly reduced arterial blood pressure in Nitric Oxide (NO) synthase inhibitor (L-NAME)-induced hypertensive male rats ${ }^{7}$.

The ability of the Tridax procumbens leaf extract to significantly reduce arterial blood pressure in hypertensive rats opened a vista in the mechanistic study of the vasorelaxant activities of AETPL. The prospect of Tridax procumbens leaf extract as an antihypertensive agent prompted us to investigate its effect on erec- 
tile tissues and reproductive functions. The relationship between hypertension/endothelial dysfunction and erectile dysfunction is well-established ${ }^{8}$. A previous study had reported a concentration-dependent relaxant effect by the ethanol extract of Tridax procumbens leaf in rats' corpus cavernosum ${ }^{9}$. The relaxation was proposed to be mediated by NO release ${ }^{9}$. NO release was suggested in the study because pretreatment with L-NAME did not completely inhibit the relaxant effect of Tridax procumbens.

Recently, we reported ${ }^{10}$ that AETPL treatment in L-NAME-induced hypertensive male rats reduced blood pressure and attenuated reproductive function impairments. Fertility success was $100 \%$, and sperm count, motility, viability, and serum testosterone were enhanced. Furthermore, AETPL treatment in L-NAME-induced hypertensive male rats promoted the relaxant effect on isolated corpus cavernosum strips (CS) ${ }^{11}$. It was observed that phenylephrine (PHE), potassium chloride ( $\mathrm{KCl})$, and calcium chloride $\left(\mathrm{CaCl}_{2}\right)$-mediated contraction were substantially inhibited in the corpus cavernosum. Relaxant responses to sodium nitroprusside and acetylcholine (ACh) were also much improved. It was suggested in the study that the relaxant activity of AETPL may act via NO donor and its strong antioxidant properties. Drugs that could increase NO donor/synthesis in cavernosal bodies are of interest in erectile dysfunction management and treatment ${ }^{12}$.

The preliminary prospect shown by AETPL in attenuating impaired contractile functions in hypertensive rats provided us with the impetus to presently investigate the ability of AETPL to reverse erectile dysfunction (and what the probable mechanisms involved in this could be) specifically. This study analyzes the mechanism of AETPL-induced contractile activity of the corpus cavernosum in paroxetine-induced erectile dysfunctional male rats. Nicorandil (mediator of corpus cavernosum relaxation by $\mathrm{K}_{A T P}$ channel opening action and NO donor activity), adenosine (endogenous vasodilator in penile erection), acetovanillone (NADPH oxidase inhibitor), nifedipine (L-type calcium channel inhibitor), indomethacin (non-specific COX inhibitors), and caffeine (non-selective inhibitor of phosphodiesterase five inhibitor [PDE]) were used. This was at further elucidating the relaxant mechanisms of AETPL. Paroxetine induces erectile dysfunction ${ }^{13}$ by inhibiting NO synthase (NOS) activity and NO synthesis. NO is a key mediator in penile erection ${ }^{14}$. Viagra (sildenafil citrate), used as a reference drug in this study, is a PDE used in the treatment of $\mathrm{ED}^{15}$. PDEs are predominantly expressed in the corpus cavernosum. They (through the NO/cGMP signaling pathway) restrain smooth muscle cell relaxation and subsequently inhibit erectile processes ${ }^{15}$.

\section{METHODS}

\section{Animals, acclimatization, and ethics ap- proval}

A total of 20 adult male Wistar albino rats (150 $200 \mathrm{~g}$ ) were used. The animals were acclimatized for two weeks under conventional laboratory conditions (12-hour light-dark cycle at $18-26{ }^{\circ} \mathrm{C}$ and relative humidity of $30 \%-70 \%$ ) and allowed free access to a standard pellet diet (Ladokun Feeds Nigeria Ltd.) and water. Standard procedure (NIH guide) for the safety and use of laboratory animals was adhered to throughout the study. The procedures for animal use were also certified by the Lagos State University College of Medicine Animal Ethics Committee.

\section{Collection and aqueous extraction from Tri- dax procumbens leaves}

Tridax procumbens leaves were collected from Lagos State University College of Medicine Ikeja, Lagos State, Nigeria, between September and October 2019. The sample of the plant was authenticated by a certified taxonomist. Leaves of Tridax procumbens were air-dried and then blended into a fine powder, then $1,000 \mathrm{~g}$ of this powder was placed in a conical flask containing $1,000 \mathrm{~mL}$ of distilled water. The mixture was shaken thoroughly and then allowed to sit for 72 hours. The filtrate was then obtained using Whatman filter paper and concentrated by evaporation in a water bath $\left(35-40{ }^{\circ} \mathrm{C}\right)^{8}$. The yield for the extraction was $35 \%$ of a light-brown powdery extract.

\section{Experimental design and treatment}

There were four groups of five male rats each for this study. Group 1 (control) received distilled water, while groups 2, 3, and 4 received $10 \mathrm{mg} / \mathrm{kg}$ paroxetine $^{16}$. However, groups 3 and 4 were co-treated with $100 \mathrm{mg} / \mathrm{kg} \mathrm{AETPL}^{10}$ and $0.5 \mathrm{mg} / \mathrm{kg}$ Viagra $^{17}$, respectively. All treatments were performed daily via oral gavage for four weeks. The body weights of the animals were monitored using an HCB 1002 scale (Adams Equipment, UK).

\section{Drugs and chemicals for experiments}

The paroxetine was manufactured by Medreich PLC, $\mathrm{UK}$, and the Viagra was manufactured by Zim Laboratories Ltd., Nagpur, India. PHE and $\mathrm{CaCl}_{2}$ were purchased from Tocris, UK. N-nitro-l-arginine 
methyl ester (L-NAME), acetovanillone, and nicorandil were purchased from AK Scientific, Inc., CA, USA. Adenosine, ACh, $\mathrm{KCl}$, and caffeine were purchased from Research Chemicals Ltd., Heysham, Lancs, UK. Nifedipine was bought from Unicure Pharmaceutical Co. Ltd., Lagos, Nigeria, and indomethacin from Jiangxi Pharmaceutical Co., Ltd., Jiangxi, China.

\section{Animal sacrifice and preparation of corpus cavernosum strips}

Animals were anesthetized with sodium pentobarbital $(30 \mathrm{mg} / \mathrm{kg}$ ) before being sacrificed by cervical dislocation. The penis was surgically removed as a whole and carefully placed in a petri-dish containing physiological salt solution (PSS). The corpus cavernosum tissue was then isolated and carefully dissected from the surrounding tunica albuginea as previously described ${ }^{11}$. The CSs were suspended in a 50-ml chamber of organ bath. The chamber contains PSS consisting of the following in $\mathrm{m} / \mathrm{mol}: \mathrm{KCl}(0.35)$; $\mathrm{KH}_{2} \mathrm{PO}_{4}$ (0.16), $\mathrm{MgSO}_{4} 7 \mathrm{H}_{2} \mathrm{O}$ (0.29), $\mathrm{NaCl}$ (6.96), $\mathrm{CaCl}_{2}$ (0.24), $\mathrm{NaHCO}_{3}$ (2.1), and D-Glucose (2.1). One end of the cavernosal strips were anchored in the organ chamber and the other end to a force isometric transducer (model 7004; Ugo-Basile Varese, Italy), which was, in turn, connected to a Data Capsule Acquisition System Model 17,400 for recording isometric contractions.

\section{Contractile study on cavernous tissue strips Contractile responses of Corpus cavernosum strips to cumulative doses of $P H E, K C l, A C h$, and $\mathrm{CaCl}_{2}$}

The tissue was allowed to stabilize in the physiological solution for 90 minutes, during which it was stimulated three times at 30-minute intervals with $\mathrm{PHE}$ $\left(10^{-7}\right)$. Contractile responses of the CS from each group to cumulative doses of ACh $\left(10^{-9}-10^{-5} \mathrm{M}\right)$, PHE $\left(10^{-9}-10^{-5} \mathrm{M}\right)$, and $\mathrm{KCl}$ were determined. Contractile responses to $\mathrm{CaCl}_{2}$ were determined by adding $\mathrm{CaCl}_{2}$ cumulatively $(10-50 \log \mathrm{M})$ to the calcium-free solution in the organ chamber. The responses were at a steady level before the addition of another dose. Tissues were washed three times between each drug administration.

\section{Contractile responses of corpus cavernosum strips after pre-incubation}

1. The influence of NO synthase inhibitor was investigated by incubating cavernosal strips from across the groups in L-NAME $\left(10^{-4} \mathrm{M}\right)$ for
15 minutes. Contractile responses to cumulative doses of acetylcholine $\left(10^{-9}-10^{-5} \mathrm{M}\right)$ were then recorded.

2. The cyclo-oxygenase inhibitor activity in the cavernous strips from all the groups was examined by incubating the cavernous strips in indomethacin $\left(10^{-4} \mathrm{M}\right)$ for 15 minutes. Contractile responses to cumulative doses of ACh $\left(10^{-9}-10^{-5} \mathrm{M}\right)$ were then recorded.

3. The voltage-gated large-conductance calcium channel activity in the cavernosal strips from all the groups was analyzed by incubating cavernosal strips from all the groups in nifedipine

4. The KATP channel and NO donor activity in the cavernosal strips from all the groups were investigated by incubating the cavernosal strips in nicorandil $\left(10^{-4}\right)$ for 15 minutes. Contractile responses of the cavernosal strips to cumulative doses of $\mathrm{ACh}\left(10^{-9}-10^{-5} \mathrm{M}\right)$ were then recorded.

5. The influence of NADPH oxidase inhibitor on the contractile activity of the cavernosal strips from all the groups was examined by incubating the strips in acetovanillone $\left(10^{-4} \mathrm{M}\right)$ for 15 minutes. Contractile responses of the strips to cumulative doses of ACh $\left(10^{-9}-10^{-5} \mathrm{M}\right)$ were then recorded.

6. Furthermore, the non-selective phosphodiesterase activity in the cavernosal strips from all the groups was investigated by incubating the strips in caffeine $\left(10^{-4} \mathrm{M}\right)$ for 20 minutes. Contractile responses of the cavernosal strips to cumulative doses of PHE $\left(10^{-9}-10^{-5} \mathrm{M}\right)$ were then recorded.

7. The membrane hyperpolarization and $\mathrm{K}^{+}$efflux in the cavernosal strips from all the groups were analyzed by incubating cavernosal strips in adenosine $\left(10^{-4} \mathrm{M}\right)$ for 20 minutes. Contractile responses of the cavernosal strips to cumulative doses of PHE $\left(10^{-9}-10^{-5} \mathrm{M}\right)$ were then recorded.

\section{Statistical analysis and data representation}

Data were analyzed using Prism GraphPad (version 5) statistical software. Data were presented as mean \pm standard error of the mean (SEM). One-way ANOVA with Neuman-Keuls posthoc-test was determined, and statistical significance was taken at $\mathrm{p}<0.05$. 
$\mathbf{A}$

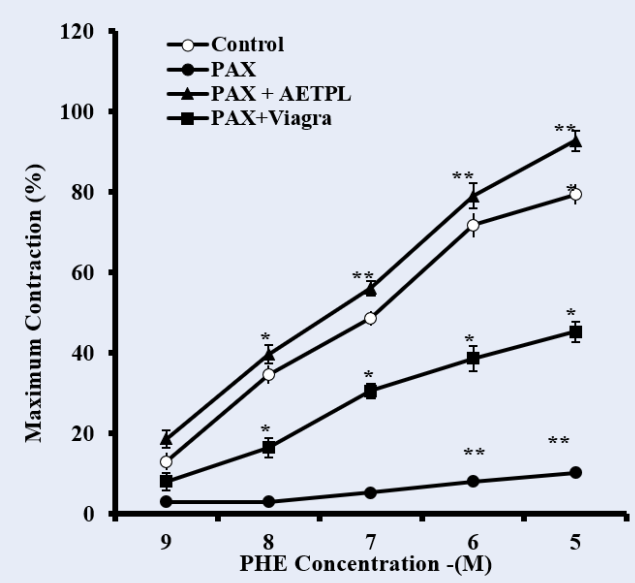

B

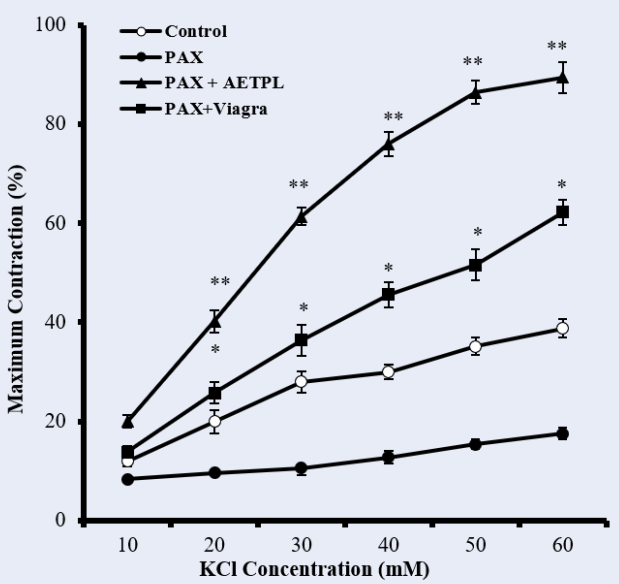

Figure 1: Contraction responses (\%) of cavernosal strips from control, paroxetine treated (PAX), paroxetine + AETPL treated (PAX+AETPL), and paroxetine + Viagra treated (PAX + Viagra) groups to cumulative doses of PHE (A) $\left(10^{-9}-10^{-5} \mathrm{M}\right)$, and $\mathrm{KCl}(\mathrm{B})(10-60 \mathrm{M}) . \mathrm{N}=5,{ }^{*} \mathrm{p}<0.05,{ }^{* *} \mathrm{p}<0.01$

A

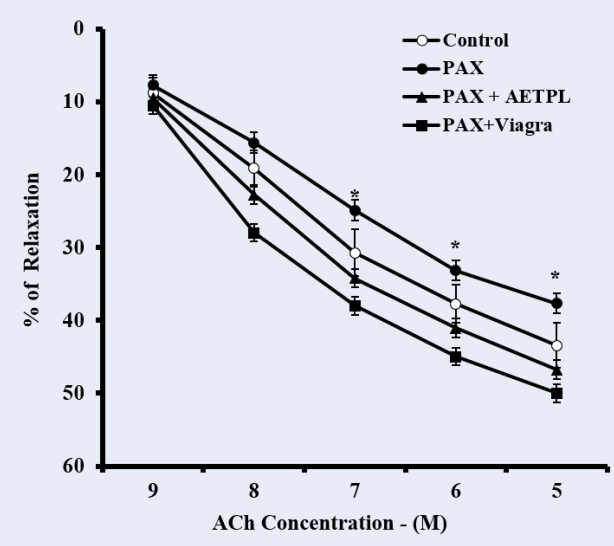

B

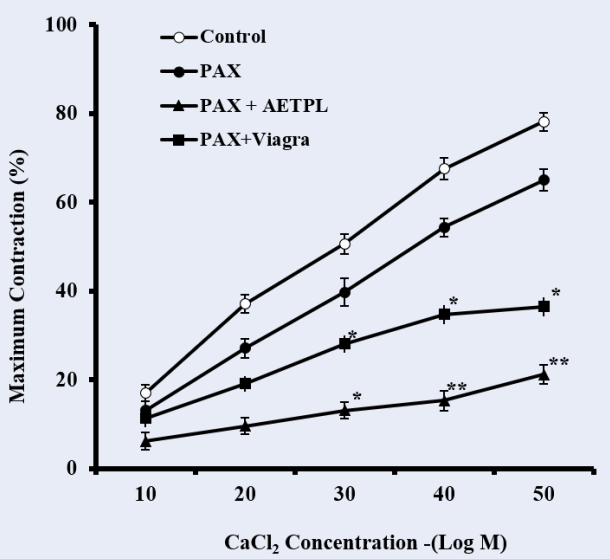

Figure 2: Percentage relaxation (A) of cavernous strips to cumulative doses of $\mathrm{ACh}\left(10^{-9}-10^{-5} \mathrm{M}\right)$, and contraction responses (\%) (B) of cavernosal strips to cumulative doses of $\mathrm{CaCl}_{2}(10-50 \mathrm{M})$ from control, paroxetine treated (PAX), paroxetine + AETPL treated (PAX + AETPL), and paroxetine + Viagra treated (PAX + Viagra) groups. $N=5,{ }^{*} p<0.05,{ }^{* *} p<0.01$

\section{RESULTS}

Contractile responses of cavernosal strips to cumulative doses of $\mathrm{PHE}, \mathrm{KCl}, \mathrm{ACh}$, and $\mathrm{CaCl}_{2}$

Group co-treated with AETPL showed a significant and dose-dependent increase in contractile responses to PHE (18.7\%, 39.7\%, 56.2\%, 79.1\%, 92.8\%) and $\mathrm{KCl}$ (20\%, 40.2\%, 61.4\%, 76\%, 86.4\%, 89.4\%) (Figure 1).
However, contraction responses were significantly inhibited in the paroxetine-only treated group $(7.7 \%$, $15.6 \%, 24.9 \%, 33.2 \%, 37.7 \%$ for PHE and $8.4 \%$, $9.6 \%, 10.6 \%, 12.8 \%, 15.4 \%, 17.6 \%$ for $\mathrm{KCl})$. Furthermore, the percentage relaxation responses to ACh were considerably inhibited in the paroxetine-only group $(7.7 \%, 15.6 \%, 24.9 \%, 33.2 \%, 37.7 \%)$ compared to the AETPL-co-treated $(9.5 \%, 22.8 \%, 34.2 \%, 44.1 \%$, $46.8 \%)$ and the Viagra-co-treated groups (10.5\%, 
28\%, 38\%, 45\%, 50\%) (Figure 2A). Contractile responses to cumulative doses of $\mathrm{CaCl}_{2}(10-50 \mathrm{M})$ were significantly inhibited in groups co-treated with AETPL (6.2\%, 9.6\%, 13.1\%, 15.3\%, 21.2\%) and Viagra $(11.3 \%, 19.1 \%, 28.1 \%, 34.7 \%, 36.5 \%)$ compared to the one treated with paroxetine alone $(13.1 \%, 27.1 \%$, $39.7 \%, 54.3 \%, 65 \%$ ) (Figure 2 B).

\section{Contractile responses of corpus caver- nosum strips after pre-incubation}

Pre-incubation in L-NAME (Figure 3) and indomethacin (Figure 4) significantly enhanced percentage relaxation in groups co-treated with AETPL (25.5\% and $43.8 \%$ in L-NAME and indomethacin, respectively) and Viagra (30.1\% and $40.8 \%$ for L-NAME and indomethacin, respectively), compared to the paroxetine-only treated group $(9.6 \%$ and $30.5 \%$ for LNAME and indomethacin, respectively). Nevertheless, pre-incubation with nifedipine failed to enhance the percentage relaxation in groups co-treated with AETPL (1.2\%, 6\%, 10.2\%, 13.2\%, 15.3\%) and Viagra $(2.5 \%, 11.1 \%, 15.5 \%, 18.9 \%, 21.1 \%)$ (Figure 5).

The incubation of cavernosal strips in caffeine (Figure 6) and adenosine (Figure 7) resulted in significant inhibition of contractile activity of the strips to cumulative doses of PHE $\left(10^{-9} 10^{-5} \mathrm{M}\right)$ in AETPLco-treated $(5.7 \%, 11 \%, 14.5 \%, 20.3 \%, 22 \%$, and $8 \%$, $14.2 \%, 25.4 \%, 31.2 \%, 40.6 \%$ for caffeine and adenosine, respectively) and the Viagra co-treated groups (6.3\%, $17.2 \%, 21.5 \%, 26 \%, 28.8 \%$ and $10.2 \%, 19.2 \%$, $34 \%, 45.4 \%, 50.8 \%$ for caffeine and adenosine, respectively) compared to the paroxetine-only group (17.5\%, 40.5\%, 69.7\%, 83\%, 91\% and $19.2 \%, 48.6 \%$, $67.8 \%, 75.2 \%, 80.2 \%$ for caffeine and adenosine, respectively).

As shown in Figure 8, the pre-incubation of cavernosal strips with nicorandil $\left(10^{-4} \mathrm{M}\right)$ enhanced the percentage relaxation to cumulative doses of ACh $\left(10^{-9} 10^{-5} \mathrm{M}\right)$ in groups co-treated with AETPL $(9.4 \%, 20.4 \%, 29.2 \%, 39.4 \%, 43.1 \%)$ and Viagra (8.7\%, $23.5 \%, 34.5 \%, 48.4 \%, 57.7 \%)$. However, this was significantly reduced in the paroxetine-only treated group (9.3\%, 17.2\%, 23.2\%, 30.3\%, 35.6\%) (Figure 8). Pre-incubation of cavernosal strips with acetovanillone $\left(10^{-4} \mathrm{M}\right)$ enhanced the percentage relaxation to cumulative doses of ACh $\left(10^{-9} 10^{-5} \mathrm{M}\right)$ across groups (paroxetine-only 63.7\%, AETPL-co-treated $52.6 \%$, and Viagra-co-treated 56.5\%) (Figure 9).

\section{DISCUSSION}

The thrust of this study was to elucidate the mechanisms involved in the reversal of erectile dysfunction by AETPL treatment in adult male rats. This study revealed key mechanisms involved in the reversal of paroxetine-induced erectile dysfunction of the corpus cavernosum by AETPL.

\section{$\mathrm{KCl}, \mathrm{PHE}, \mathrm{ACh}$, and NADPH oxidase inhibitor activity}

Inhibited/impaired contractile activity to PHE and $\mathrm{KCl}$ was observed in the cavernous strips of the group treated with paroxetine alone. Co-treatment with AETPL was able to reverse the inhibition to contractile activity in response to $\mathrm{PHE}$ and $\mathrm{KCl}$ (Figure 1). Likewise, ACh-induced relaxation was most repressed in paroxetine-only treated rats compared to groups co-treated with AETPL (Figure 2 A). Nonetheless, the incubation of cavernous strips in apocynin/acetovanillone, which is a free radical scavenger and NADPH oxidase inhibitor ${ }^{18}$, was able to enhance the cavernous strips' relaxation responses to cumulative doses of ACh in all groups (Figure 9). Ordinarily, alpha-adrenergic receptor agonist (PHE) and high $\mathrm{K}^{+}{ }^{19}$ are known to enhance contractile activities in the corpus cavernosum. However, the damage that was done by the paroxetine treatment impaired this function as observed in this study, and cotreatment with AETPL was able to reverse the inhibition and significantly enhance the cavernous strips' contractile activity in response to these agonists. Earlier, we observed a similar protective role where AETPL treatment was able to attenuate impaired cavernous strips contractile activity in L-NAME-induced hypertensive male rats ${ }^{11}$.

The key pathophysiology in erectile dysfunction is the reported role of oxidative stress in causing endothelial dysfunction in erectile tissues ${ }^{20}$. Paroxetine is reported to cause erectile dysfunction by inhibiting the activity of NOS. Results from this study highlight paroxetine-induced damage in endothelial, smooth muscle functions by the generation of reactive oxygen species (ROS). However, we suggest this was mopped up in the CS during the incubation with apocynin and may be responsible for the comparable relaxation responses in the paroxetine-only, the AETPL-co-treated, and the Viagra co-treated groups after incubation in apocynin (Figure 9). Viagra can prevent erectile tissue damage as shown in this study. It has been earlier reported that Viagra prevented endothelial dysfunction in cavernous tissues ${ }^{21}$ and vardenafil; an analog was reported to reverse erectile dysfunction induced by paroxetine in rats ${ }^{22}$. In the AETPL-co-treated group, however, we speculate 


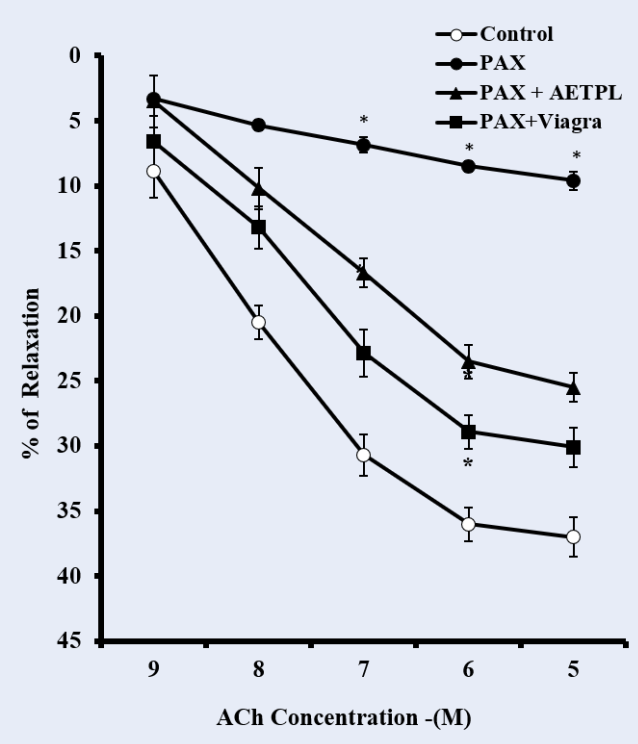

Figure 3: Percentage of relaxation of cavernosal strips to cumulative doses of ACh $\left(10^{-9}-10^{-5} \mathrm{M}\right)$ after incubation in L-NAME $\left(10^{-4} \mathrm{M}\right)$ in control, paroxetine treated (PAX), paroxetine + AETPL treated (PAX + AETPL), and paroxetine + Viagra treated (PAX + Viagra) groups. $N=5,{ }^{*} p<0.05$.

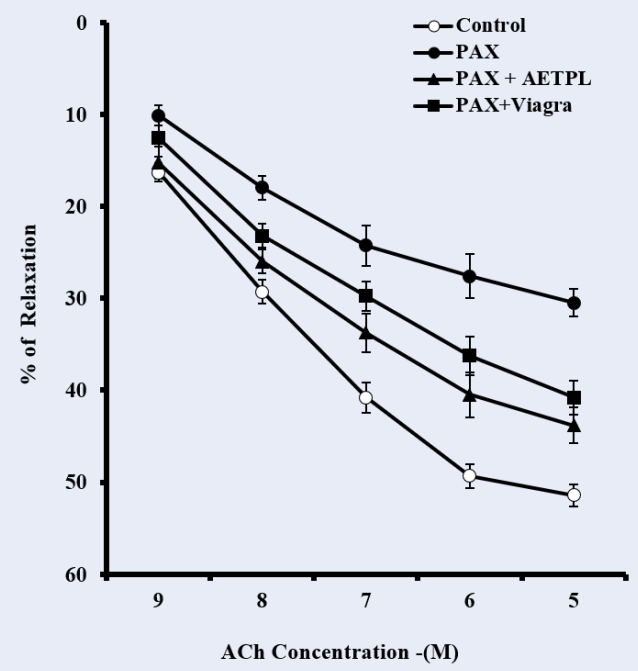

Figure 4: Percentage of relaxation of cavernosal strips to cumulative doses of $\mathrm{ACh}\left(10^{-9}-10^{-5} \mathrm{M}\right)$ after incubation in indomethacin $\left(10^{-4} \mathrm{M}\right)$ in control, paroxetine treated (PAX), paroxetine + AETPL treated (PAX + AETPL), andparoxetine + Viagra treated (PAX + Viagra) groups. $N=5,{ }^{*} p<0.05$ 


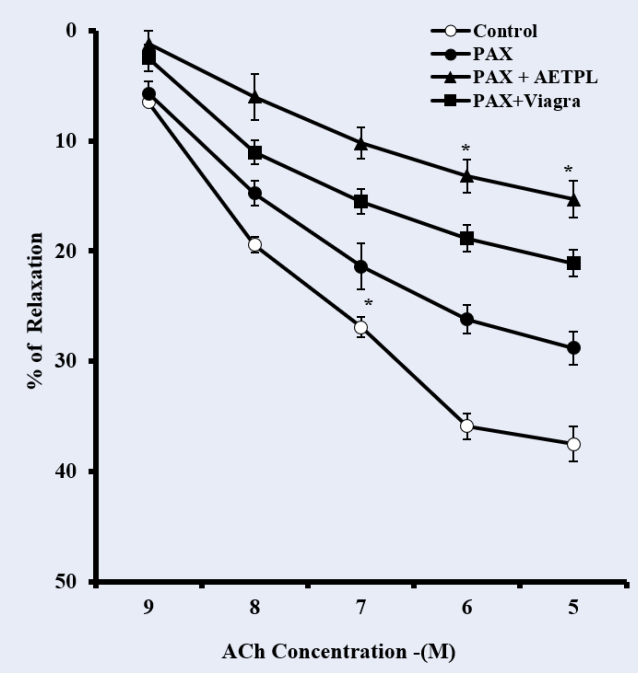

Figure 5: Percentage of relaxation of cavernosal strips to cumulative doses of $\mathrm{ACh}\left(10^{-9}-10^{-5} \mathrm{M}\right)$ after incubation in nifedipine $\left(10^{-4} \mathrm{M}\right)$ in control, paroxetine treated (PAX), paroxetine + AETPL treated (PAX + AETPL), and paroxetine + Viagra treated (PAX + Viagra) groups. $N=5,{ }^{*} p<0.05$

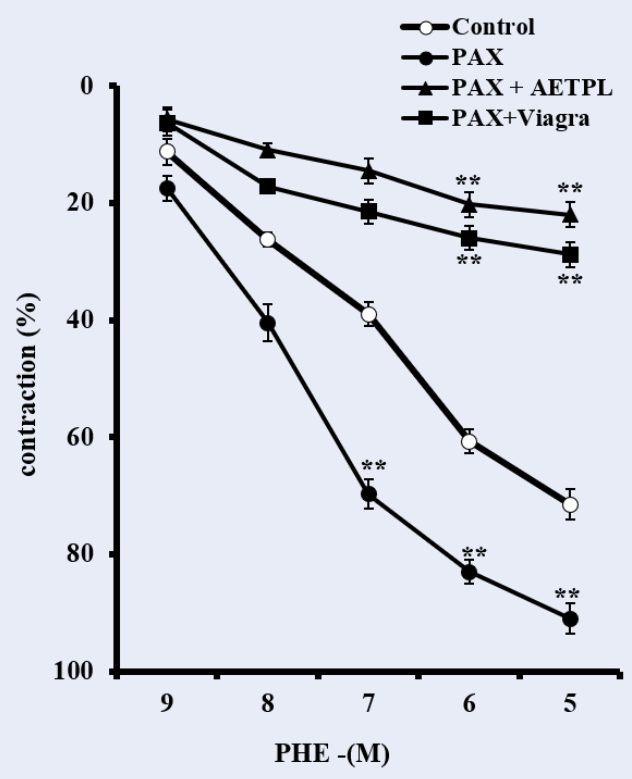

Figure 6: Contraction responses (\%) of cavernosal strips to cumulative doses of $\mathrm{PHE}\left(10^{-9}-10^{-5} \mathrm{M}\right)$ after incubation in caffeine $\left(10^{-4} \mathrm{M}\right)$ in control, paroxetine treated (PAX), paroxetine + AETPL treated (PAX + AETPL), and paroxetine + Viagra treated (PAX + Viagra) groups. $N=5,{ }^{* *} \mathrm{p}<0.01$ 


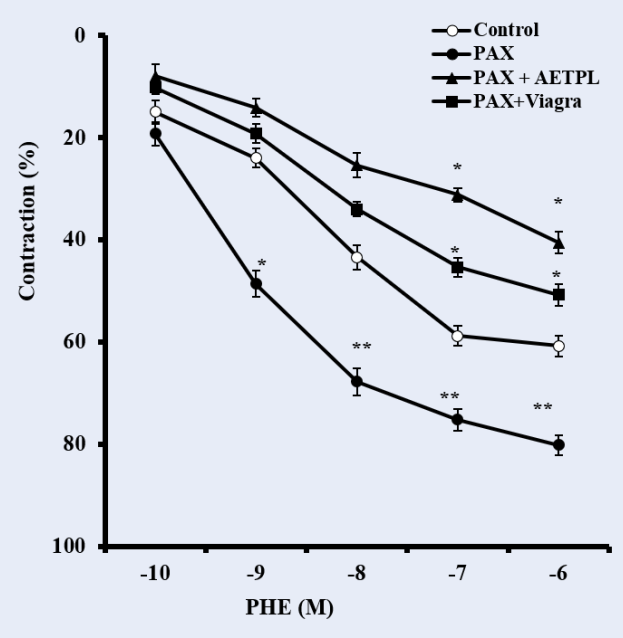

Figure 7: Contraction response (\%) of cavernosal strips to cumulative doses of PHE $\left(10^{-9}-10^{-5} \mathrm{M}\right)$ after incubation in adenosine $\left(10^{-4} \mathrm{M}\right)$ in control, paroxetine treated (PAX), paroxetine + AETPL treated (PAX + AETPL), and paroxetine + Viagra treated (PAX +Viagra) groups. $N=5,{ }^{*} p<0.05,{ }^{* *} p<0.01$

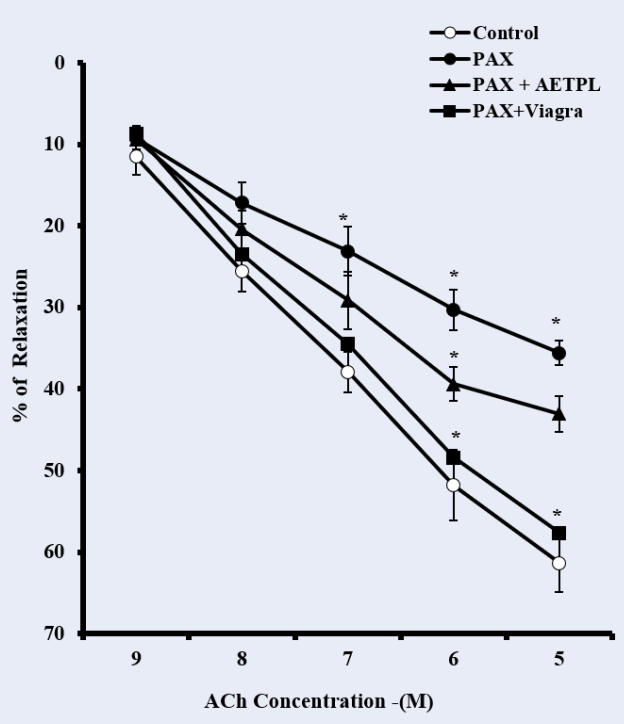

Figure 8: Percentage relaxation of cavernosal strips to cumulative doses of $\mathrm{ACh}\left(10^{-9}-10^{-5} \mathrm{M}\right)$ after incubation in nicorandil $\left(10^{-4} \mathrm{M}\right)$ in control, paroxetine treated (PAX), paroxetine + AETPL treated (PAX + AETPL), and paroxetine + Viagra treated (PAX +Viagra) groups. $N=5,{ }^{*} p<0.05$. 


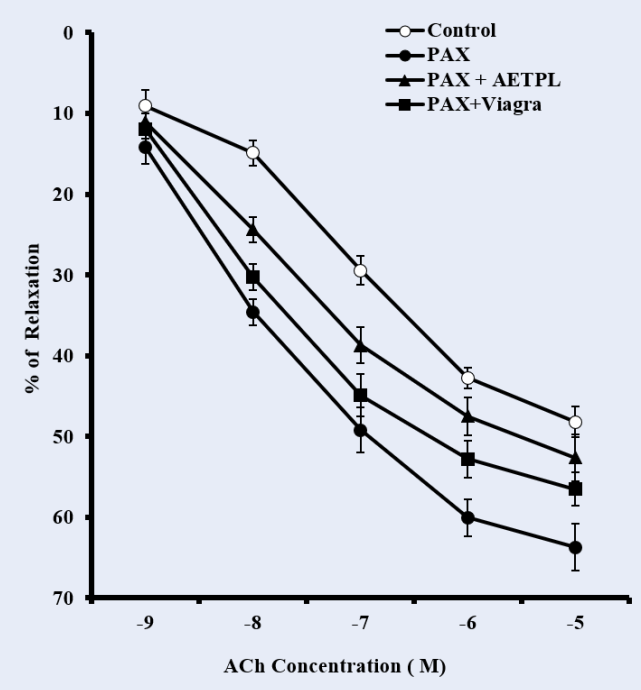

Figure 9: Percentage relaxation of cavernosal strips to cumulative doses of $\mathrm{ACh}\left(10^{-9}-10^{-5} \mathrm{M}\right)$ after incubation in acetovanillone $\left(10^{-4} \mathrm{M}\right)$ in control, paroxetine treated (PAX), paroxetine + AETPL treated (PAX + AETPL), and paroxetine + Viagra treated (PAX + Viagra) groups. $N=5$

that the strong antioxidant properties of AETPL offered protection against erectile tissue damage. Substantial antioxidants, such as quercetin, Vitamins E \& C, flavonoids, and linoleic acid, have been reported present in AETPL ${ }^{1,2}$.

\section{L-type calcium channel, NOS, and COX in- hibitors activity}

The incubation of cavernous strips in nifedipine (Figure 5) failed to enhance the relaxation of cavernous strips to cumulative doses of $\mathrm{ACh}$, which suggests that L-type calcium channel inhibitor activity only partly contributes to the relaxant activity of AETPL. Nevertheless, contraction in response to extracellular calcium influx was significantly inhibited in the AETPL-co-treated group (Figure 2 B). The ability of AETPL to stimulate non-competitive and nonspecific inhibition of calcium influx and mobilization from stores has been reported previously for rats' aorta ${ }^{5}$. Preliminary results from this study indicate that a similar mechanism may be at play in the corpus cavernosum. This suggests a definitive yet fully unclear role for calcium in the relaxant activity of AETPL in the corpus cavernosum.

The incubation of cavernous strips in NOS inhibitor (L-NAME) did not adversely impair the percentage of relaxation response to $\mathrm{ACh}$ in groups co-treated with AETPL and Viagra (Figure 3). Relaxation to ACh was significantly inhibited in the paroxetine-only treated group after L-NAME incubation. Defective NO activity is reported to play a role in the pathogenesis of erectile dysfunction ${ }^{23}$. The reduced relaxation in the paroxetine-only treated group is obvious due to reported inhibition to NOS and expression of nNOS by paroxetine ${ }^{14}$. The ability of the AETPL-co-treated group to a show comparable relaxation response, like the Viagra-co-treated group, suggests that it could have enhanced the activity of NOS as reported for Viagra $^{21}$. It is also rational to posit that AETPL acted as a NO donor as previously suggested ${ }^{9}$. In the recent past, drugs that increase NO synthesis in cavernosal bodies were of great interest for ED treatment. One of such ruthenium, was reported to mediate relaxation in rabbit corpus cavernosum smooth muscle by its NO release activity ${ }^{24}$.

The incubation of cavernous strips from all the groups in cyclooxygenase inhibitor (indomethacin) resulted in a relaxation of $43 \%$ in the AETPL-co-treated group compared to $30 \%$ in the paroxetine-only treated group (Figure 4). Indomethacin is a non-steroidal anti-inflammatory drug. Tridax procumbens leaf has also recently bee reported to reduce the expression of inflammatory mediators ${ }^{25}$. It can be safely assumed that treatment with AETPL coupled with incubation in indomethacin synergistically inhibited inflammation and the production of inflammatory markers. Although inflammatory markers were not determined in this study, it will be worthwhile to investigate their role in AETPL-mediated activity in cavernous tissues. 
$\mathbf{K}_{A T P}$ channel and non-selective phosphodiesterase activity

In this study, cavernous strips from the Viagra-cotreated and the AETPL-co-treated groups showed comparably enhanced relaxation to cumulative doses of ACh after incubation in nicorandil. However, this was absent for the paroxetine-only treated group (Figure 8). The comparable relaxation effects shown in the AETPL-co-treated and the Viagra-co-treated groups indicate the likelihood that they both share relaxation mechanisms in the corpus cavernosum. Another plausible postulate is that AETPL treatment will not interfere, but rather, potentiate relaxant activity as mediated by nicorandil. Besides, nicorandil is reported to effectively relax the corpus cavernous by stimulating $\mathrm{K}_{A T P}$ channels and soluble guanylyl cyclase $^{26}$. Recently, nicorandil is also suggested to be a $\mathrm{NO}$ donor ${ }^{27}$. Viagra-induced prevention of endothelial dysfunction by activation of ATP-sensitive $\mathrm{K}^{+}$channels, similar to what nicorandil does in cavernous tissue, is reported by Gori et al. ${ }^{21}$. Furthermore, Viagra is known to activate NOS to produce NO and guanylyl cyclase to enhance relaxation.

It was also observed in this study that pre-incubation in caffeine was able to significantly inhibit PHEinduced contractile activity in the corpus cavernosum of AETPL and Viagra co-treated groups (Figure 6). Caffeine is a non-selective inhibitor of phosphodiesterases (PDEs) ${ }^{28}$. It was also reported to upregulate cGMP $^{29}$ and decrease $\mathrm{Ca}^{2+}$ influx and sensitivity in the corpus cavernosum. Adeniyi and Adaikan ${ }^{19}$ had earlier suggested a caffeine-induced decrease in $\mathrm{Ca}^{2+}$ influx and sensitivity in the cavernous contractile activity after infusion of noradrenaline. The particular caffeine-mediated mechanism potentiated by AETPL is currently unknown. However, the inhibition of calcium influx and reduced calcium sensitivity had earlier been reported for AETPL relaxant action in rats' aorta $^{5}$. We also reported in this study that increasing the concentration of $\mathrm{Ca}^{2+}$ in the calcium-free solution inhibited contractile activity in the corpus cavernosum of the AETPL-co-treated group (Figure 2 B).

\section{Adenosine mediated and hyperpolariza- tion activity}

Incubation of corpus cavernosum strips in adenosine significantly inhibited contraction in response to cumulative doses of PHE in the AETPL-co-treated group (Figure 7). Adenosine via adenosine receptor signaling is known to decrease cAMP, which leads to hyperpolarization and $\mathrm{K}^{+}$efflux, which, in turn, inhibit the $\mathrm{Ca}^{2+}$ current, resulting in relaxation ${ }^{29}$.
According to the results of this study, AETPL treatment did not impair the adenosine-mediated mechanism involved in erectile tissue relaxation. Moreover, the adenosine pathway may have contributed to the AETPL-induced reversal of erectile dysfunction in the AETPL-co-treated group. Phatarkar et al. ${ }^{30}$ observed that erectile dysfunction is mostly present in impaired adenosine signaling, and Wen and $\mathrm{Xia}^{31}$ have reported that adenosine is a key endogenous vasodilator in the maintenance of an erection.

The fact that we were not able to identify the specific constituent/constituents in AETPL that is/are responsible for the reversal of erectile dysfunction in this study is a limitation. We earlier reported the presence of octadecatrienoic acid (65.57\%), octadecadienal $(9.47 \%)$, chloropropionic acid, octadecyl ester (9.22\%), and butyl 9,12-octadecadienoate (8.76\%) in AETPL after gas chromatography and molecular spectrometry (GC-MS) analysis ${ }^{6}$. The octadecatrienoic acid in AETPL is linolenic acid, for which dilatory properties have been reported in the literature $^{6}$. We believe its rich presence in AETPL contributed to the relaxant activities of AETPL in cavernosal tissues in this study. Furthermore, preliminary observations from this study are indicative of AETPL's potential in reversing erectile dysfunction. It is instructive to note that Tridax procumbens plant belongs to the Asteraceae family, and the Asteraceae family has long been used in Persian medicine Nimrouzi et al., ${ }^{32}$ in treating impotence and erectile dysfunction.

\section{CONCLUSIONS}

This study found that AETPL was able to reverse paroxetine-induced erectile dysfunction in the corpus cavernosum of rats. This could be mediated by AETPL-induced antioxidant/NADPH oxidase inhibitor activity, reduced sensitivity to calcium, activation of ATP-sensitive $\mathrm{K}^{+}$channel, and endothelial NO release.

\section{ABBREVIATIONS}

Ach: Acetylcholine

AETPL: Aqueous extract of Tridax procumbens leaf $\mathrm{CaCl}_{2}$ : Calcium chloride

cAMP: cyclic adenosine monophosphate

cGMP: cyclic guanylyl monophosphate

CS: cavernous strip

ED: Erectile dysfunction

eNO: endothelia nitric oxide

$\mathbf{K}_{A T P}$ : adenosine triphosphate sensitive potassium channel

KCl: Potassium chloride 
L-NAME: N-nitro-L-arginine methyl ester

NADPH: Nicotinamide adenine dinucleotide phosphate hydrogenase

NIH: National Institute of Health

nNO: neuronal nitric oxide

NO: Nitric oxide

NOS: nitric oxide synthase

PDE: Phosphodiesterase

PHE: Phenylephrine

\section{ACKNOWLEDGMENTS}

Authors acknowledge the assistance of Shuaib and Segun.

\section{AUTHOR'S CONTRIBUTIONS}

Conceptualization: SAS, Methodology: SAS \& HMS, Software: SAS, HMS \& BAM, Validation: SAS, HMS, Formal Analysis: SAS, HMS \& BAM, Investigation: ZAB, BAM, Resources: SAS, HMS, ZAB, Data Curation: SAS,HMS,ZAB,BAM,YR, Writing Original Draft: SAS, Writing - Review \&, Editing: SAS,HMS,YR,BAM, Supervision: SAS. All authors read and approved the final manuscript.

\section{FUNDING}

None.

\section{AVAILABILITY OF DATA AND MATERIALS}

Data and materials used and/or analyzed during the current study are available from the corresponding author on reasonable request.

\section{ETHICS APPROVAL AND CONSENT TO PARTICIPATE}

Not applicable.

\section{CONSENT FOR PUBLICATION}

Not applicable.

\section{COMPETING INTERESTS}

The authors declare that they have no competing interests.

\section{REFERENCES}

1. Petchi RR, Vijaya C, Parasuraman S. Antidiabetic activity of polyherbal formulation in streptozotocin - nicotinamide induced diabetic wistar rats. J Tradit Complement Med. 2014;4(2):108-17. PMID: 24860734. Available from: 10.4103/ 2225-4110.126174.

2. Ikewuchi CC, Ikewuchi JC, Ifenacho MO. Phytochemical composition of Tridax procumbens Linn leaves: potential as a functional food. Food Nutr Sci. 2015;6(11):992-1004. Available from: 10.4236/fns.2015.611103.
3. Salahdeen HM, Yemitan OK, Alada AR. Effect of aqueous leaf extract of Tridax procumbens on blood pressure and heart rate in rats. Afr J Biomed Res. 2004;7:27-39.

4. Salahdeen HM, Idowu GO, Murtala BA. Endotheliumdependent and independent vasorelaxant effects of aqueous extract of Tridax procumbens Lin. leaf in rat aortic rings. Indian J Exp Biol. 2012;50(12):883-8. PMID: 23986972.

5. Salahdeen HM, Idowu GO, Yemitan OK, Murtala BA, Alada AR. Calcium-dependent mechanisms mediate the vasorelaxant effects of Tridax procumbens (Lin) aqueous leaf extract in rat aortic ring. J Basic Clin Physiol Pharmacol. 2014;25(2):1616. PMID: 24127539. Available from: 10.1515/jbcpp-2013-0030.

6. Salahdeen HM, Adebari AO, Murtala BA, Alada AR. Potassium channels and prostacyclin contribute to vasorelaxant activities of Tridax procumbens crude aqueous leaf extract in rat superior mesenteric arteries. Afr J Med Med Sci. 2015;44(1):519. PMID: 26548111.

7. Salahdeen HM, Salami SA, Paul CO, Murtala BA, Alada AA. Biochemical parameters as indicators of antihypertensive efficacy of leaf aqueous extract of Tridax procumbens (Lin) in LNAME induced hypertensive rats. Journal of Molecular Pathophysiology. 2017;6(2):30-37. Available from: 10.5455/jmp. 20170721110820.

8. Maas R, Schwedhelm E, Albsmeier J, Böger RH. The pathophysiology of erectile dysfunction related to endothelial dysfunction and mediators of vascular function. Vasc Med. 2002;7(3):213-25. PMID: 12553745. Available from: 10.1191/ 1358863x02vm429ra.

9. Salahdeen HM, Idowu GO, Yemitan OK, Murtala BA, Alada AR. The relaxant actions of ethanolic extract of Tridax procumbens (Linn.) on rat corpus cavernosum smooth muscle contraction. J Basic Clin Physiol Pharmacol. 2015;26(2):211-6. PMID: 24897396.

10. Salami SA, Salahdeen HM, Rahman OC, Murtala BA, Raji Y. Oral administration of Tridax procumbens aqueous leaf extract attenuates reproductive function impairments in L-NAMEinduced hypertensive male rats. Middle East Fertil Soc J. 2017;22(1):219-25. Available from: 10.1016/j.mefs.2017.03. 001.

11. Salami SA, Salahdeen HM, Ugbebor EC, Murtala BA, Raji Y. Effects of aqueous leaf extract of Tridax procumbens on contractile activity of corpus cavernosum in N-nitro-l-arginine methyl ester-induced hypertensive male rats. J Integr Med. 2018;16(1):51-6. PMID: 29397093. Available from: 10.1016/j. joim.2017.11.001.

12. Kalsi JS, Kell PD, Cellek S, Ralph DJ. NCX-911, a novel nitric oxide-releasing PDE5 inhibitor relaxes rabbit corpus cavernosum in the absence of endogenous nitric oxide. Int J Impot Res. 2004;16(2):195-200. PMID: 14961060. Available from: 10.1038/sj.ijir.3901157.

13. Ahn GJ, Kang KK, Kim DS, Ahn BO, Kim WB, Kang SK. DA8159 reverses selective serotonin reuptake inhibitor-induced erectile dysfunction in rats. Urology. 2005;65(1):202-7. PMID: 15667904. Available from: 10.1016/j.urology.2004.09.023.

14. Angulo J, Peiró C, Sanchez-Ferrer CF, Gabancho S, Cuevas $P_{1}$ Gupta S. Differential effects of serotonin reuptake inhibitors on erectile responses, NO-production, and neuronal NO synthase expression in rat corpus cavernosum tissue. Br J Pharmacol. 2001;134(6):1190-4. PMID: 11704638. Available from: 10.1038/sj.bjp.0704351.

15. Andersson KE. Mechanisms of penile erection and basis for pharmacological treatment of erectile dysfunction. Pharmacol Rev. 2011;63(4):811-59. PMID: 21880989. Available from: $10.1124 / \mathrm{pr} .111 .004515$.

16. Yakubu MT, Jimoh RO. Carpolobia lutea roots restore sexual arousal and performance in paroxetine-induced sexually impaired male rats. Rev Int Androl. 2014;12(3):90-9. Available from: 10.1016/j.androl.2014.02.002. 
17. Dare A, Salami SA, Kunle-Alabi OT, Akindele OO, Raji Y. Comparative evaluation of the aphrodisiac efficacy of sildenafil and Carpolobia lutea root extract in male rabbits. J Intercult Ethnopharmacol. 2015;4(4):302-7. PMID: 26649235. Available from: $10.5455 /$ jice.20151101092942.

18. Li M, Zhuan L, Wang T, Rao K, Yang J, Yang J. Apocynin improves erectile function in diabetic rats through regulation of NADPH oxidase expression. J Sex Med. 2012;9(12):3041-50. PMID: 23088159. Available from: 10.1111/j.1743-6109.2012. 02960.x.

19. Adebiyi A, Adaikan PG. Effect of caffeine on response of rabbit isolated corpus cavernosum to high $\mathrm{K}+$ solution, noradrenaline and transmural electrical stimulation. Clin Exp Pharmacol Physiol. 2004;31(1-2):82-5. PMID: 14756689. Available from: 10.1111/j.1440-1681.2004.03955.x.

20. Jeremy JY, Jones RA, Koupparis AJ, Hotston M, Persad R, Angelini GD. Reactive oxygen species and erectile dysfunction: possible role of NADPH oxidase. Int J Impot Res. 2007;19(3):265-80. PMID: 17053777. Available from: 10.1038/ sj.ijir.3901523.

21. Gori T, Sicuro S, Dragoni S, Donati G, Forconi S, Parker JD. Sildenafil prevents endothelial dysfunction induced by ischemia and reperfusion via opening of adenosine triphosphatesensitive potassium channels: a human in vivo study. Circulation. 2005;111(6):742-6. PMID: 15699265. Available from: 10.1161/01.CIR.0000155252.23933.2D.

22. Angulo J, Bischoff E, Gabancho S, Cuevas P, de Tejada IS. Vardenafil reverses erectile dysfunction induced by paroxetine in rats. Int J Impot Res. 2003;15(2):90-3. PMID: 12789386. Available from: 10.1038/sj.ijir.3900950.

23. Sullivan ME, Thompson CS, Dashwood MR, Khan MA, Jeremy JY, Morgan RJ. Nitric oxide and penile erection: is erectile dysfunction another manifestation of vascular disease? Cardiovasc Res. 1999;43(3):658-65. PMID: 10690337. Available from: 10.1016/S0008-6363(99)00135-2.

24. Cerqueira JB, Gonzaga-Silva LF, Silva FO, Cerqueira JV, Oliveira RR, Moraes ME. Identification of mechanisms involved in the relaxation of rabbit cavernous smooth muscle by a new nitric oxide donor ruthenium compound. Int Braz J Urol.
2012;38(5):687-94. PMID: 23131510. Available from: 10.1590/ S1677-55382012000500015.

25. Grace VMB, Viswanathan S, Wilson DD, Kumar SJ, Sahana K, Arbin EFM, et al. Significant action of Tridax procumbens $L$. leaf extract on reducing the TNF- $\alpha$ and COX-2 gene expressions in induced inflammation site in Swiss albino mice. In flammopharmacology. 2019;28:929-938. PMID: 31487002. Available from: 10.1007/s10787-019-00634-0.

26. Hsieh GC, Kolasa T, Sullivan JP, Brioni JD. Dual mechanism of action of nicorandil on rabbit corpus cavernosal smooth muscle tone. Int J Impot Res. 2001;13(4):240-6. PMID: 11494082 Available from: 10.1038/sj.ijir.3900702.

27. Tarkin JM, Kaski JC. Nicorandil and Long-acting Nitrates: Vasodilator Therapies for the Management of Chronic Stable Angina Pectoris. Eur Cardiol. 2018;13(1):23-8. PMID: 30310466. Available from: 10.15420/ecr.2018.9.2.

28. Corbin JD, Francis SH. Molecular biology and pharmacology of PDE-5-inhibitor therapy for erectile dysfunction. J Androl. 2003;24(6):38-41. PMID: 14581493. Available from: 10.1002/j. 1939-4640.2003.tb02744.x.

29. Yang R, Wang J, Chen Y, Sun Z, Wang R, Dai Y. Effect of caffeine on erectile function via up-regulating cavernous cyclic guanosine monophosphate in diabetic rats. J Androl. 2008;29(5):586-91. PMID: 18421070. Available from: 10.2164/ jandrol.107.004721.

30. Phatarpekar PV, Wen J, Xia Y. Role of adenosine signaling in penile erection and erectile disorders. J Sex Med. 2010;7(11):3553-64. PMID: 19889148. Available from: 10. 1111/j.1743-6109.2009.01555.x.

31. Wen J, Xia Y. Adenosine signaling: good or bad in erectile function? Arterioscler Thromb Vasc Biol. 2012;32(4):845-50. PMID: 22423035. Available from: 10.1161/ATVBAHA.111. 226803.

32. Nimrouzi M, Jaladat AM, Zarshenas MM. A panoramic view of medicinal plants traditionally applied for impotence and erectile dysfunction in Persian medicine. J Tradit Complement Med. 2018;10(1):7-12. PMID: 31956553. Available from: 10.1016/j.jtcme.2017.08.008. 